\title{
Orígenes de la Cristología del Cuarto Evangelio El problema de la unidad literaria y teológica
}

\author{
CÉSAR CARbUlLANCA NúÑ̃ZZ \\ Universidad Católica del Maule (Chile) \\ ccarbullanca@ucm.cl
}

\begin{abstract}
Resumen
El artículo pretende iluminar la discusión en torno de la unidad literaria y teológica del cuarto evangelio. De modo más provocativo, ¿debemos buscar una o varias cristologías en el evangelio de Juan? Esta investigación entrega una mirada panorámica de la respuesta dada por los defensores de la teoría los estratos a la cuestión de la unidad literaria y teológica del evangelio de Juan, colocando en evidencia que la cuestión literaria está unida a una distinta cristología propuesta por estos autores. Las soluciones dadas por los autores van desde la existencia de tradiciones o un Vorlage, como recurso a un Grundschrift o Semeia Quelle y algunas soluciones híbridas a esta cuestión. Paralelamente, estas propuestas muestran diversas cristologías, así, por ejemplo, la figura de un Jesús como Theios aner, Hijo de Dios o el profeta mosaico. La teoría de los estratos ha recibido desde sus inicios una serie de objeciones de diverso tipo, calificándola como insuficiente y arbitraria, argumentando la necesidad de buscar una nueva síntesis de los estudios joánicos.
\end{abstract}

Palabras clave: Cuarto Evangelio, Cristología, teoría de los estratos, unidad literaria.

\section{Origins of the Christology of the Fourth Gospel The problem of literary and theological unity}

\begin{abstract}
The article seeks illuminate the discussion of the unit literary and theological of the fourth gospel. More provocative, Do we find one or several christologies in the Fourth Gospel? This research delivery a gaze overview of the response given by the defenders of the theory strata to the question of the unit literary and theological the Gospel of John, placing in evidence that the issue literary is linked to a different Christology proposal by these authors. The solutions given by the authors ranging from the existence of traditions or a Vorlage, as a resource to a Grundschrift or Semeia Quelle and some bybrid solutions. In Parallel these proposals show various christologies, thus, for example, the figure of a Jesus as Theios aner, Son of God or the mosaic prophet. The theory of the strata has received since its initiation a series of objections of various kinds, calling as insufficient and arbitrary, arguing the need to look for a new synthesis of the studies johannine.
\end{abstract}

Key words: Fourth Gospel, Christology, theory of stratum, literary unity.

Sacerdote de la diócesis de Talca. Doctor en Teología por la Universidad Pontificia de Comillas (España). Profesor de Sagrada Escritura en la Facultad de Ciencias Religiosas y Filosóficas de la Universidad Católica del Maule. Entre sus publicaciones recientes cabe mencionar "Melquisedec y la cristología del Evangelio de Juan" (2008), "La Encarnación. Factor de crisis en las comunidades joánicas" (2008), "El discípulo amado: una clave hermenéutica de la cristología joánica" (2008) y "Los Cánticos del Sacrificio Sabático. Aproximaciones al estudio de la mística judía" (2009).

Este artículo es parte del proyecto FONDECYT de iniciación N 11085038: "El profeta escatológico: estudio de los orígenes de la cristología del cuarto evangelio desde la tradición de 11QMelq". 


\section{Introducción}

La investigación de la cristología joánica no puede evitar plantearse la cuestión de la unidad literaria de la obra en vista de dar cuenta apropiadamente de la imagen de Cristo que pretendió entregar el evangelista; de un modo más provocativo uno puede preguntar al atender a los comentarios en uso del cuarto evangelio ¿tenemos que hablar de la cristología o de las cristologías del cuarto evangelio?, dependiendo de la respuesta dada a esta cuestión, la presentación «oficial» que dan los comentaristas acerca de la cristología joánica se distancia harto unas de otras, de tal manera, que la confusión que presenta dicha situación está lejos de disiparse.

El estudio de la unidad literaria del cuarto evangelio ha encontrado dificultades desde hace tiempo, por ejemplo, para explicar el orden del evangelio, así por ejemplo: 4, 5, 6, 7, 1-24; la escena de 7, 53-8, 11 y la inserciones 15-17 luego de 14, 31-36 y 12, 44-50, interrumpen el orden de la narración. Otras anomalías que hablan en contra de la supuesta unidad literaria y teológica se presentan en los textos con una escatología futurista: 5,$28 ; 6,39.44 \mathrm{~b}, 54 ; 12,48$ y las referencias al bautismo y cena del Señor en 3, 5; 6, 51-58; 19, 34b.

En la historia de los estudios joánicos la respuesta a la formación del evangelio joánico se ha concentrado en las soluciones que apuntan a una unidad en el origen, ya sea por el recurso a un Grundschrift, un Zeichenevangelium, o por el recurso a la unidad en el final, en donde el origen del evangelio se encontrarían tradiciones de diverso origen. Así, entonces, algunos autores que detectan estas anomalías, postulan la existencia de una fuente semeia y otra de discursos como explicación de éstas; en cambio, otros investigadores prefieren hablar de un evangelio joánico primitivo para dar cuenta de la relativa unidad de la obra ${ }^{1}$.

El artículo pretende entregar una mirada complexiva de la respuesta dada por los defensores de la teoría de los estratos a la cuestión de la unidad literaria del cuarto evangelio vinculando la propuesta de estos autores con la supuesta cristología que mostraría cada uno de estos estratos del cuarto evangelio. En la primera parte de éste, estudiaremos el problema de la unidad literaria y formación del evangelio de acuerdo a

1 Para una visión general, cfr. R. KYSAR: “The Gospel of John in Current research", vol. 9/4 Religious Studies Review (1983), 314-321; R. SCHNACKEnburg: Das Johannesevangelium I-IV, Verlag Herder, Freiburg 1979, versión en castellano, El evangelio según San Juan. Herder, Barcelona 1987, 13-19; 95-108; J. AsHTON: "Introduction. The Problem of John", en J. Ashton (ed.), Interpretation of John, T\&T Clark, 19972, 7-25; H. J. KuHN: Christologie und Wunder. Untersuchungen zu Job 1, 35-51. Verlag Friedrich Pustet, Regensburg 1988, 68. 
los autores que postulan la existencia de tradiciones o un Vorlage, centrándonos particularmente en los relatos de Jn 1, 19-34 y 6, 1-15; en un segundo momento, desarrollaremos las opiniones de quienes la exponen como recurso a un Grundschrift o Semeia quelle. En un tercer punto, presentaremos algunas soluciones híbridas a esta cuestión y como está dicho, en cada uno de estos puntos, explicitaremos el tipo de cristología, que los autores postulan para este escrito o las fases subsiguientes. En un cuarto punto, presentamos algunas reacciones y objeciones argumentadas en contra de la teoría de los estratos y finalmente entregamos algunas conclusiones que se desprenden de estas reflexiones.

\section{El problema de la unidad literaria y teológica}

En los siguientes apartados presentaremos las diversas soluciones propuestas a la cuestión planteada por la unidad literaria y teológica del cuarto evangelio. Esta presentación no pretende ser exhaustiva sino más bien pretende exponer ante el público de habla castellana la discusión científica acerca del cuarto evangelio y las posturas que presentan.

\subsection{La existencia de tradiciones o un Vorlage}

R. Bultmann no habla de Grundschrift, ya que él cree distinguir la existencia de diversas fuentes pre-joánicas entre las que enumeró, un himno, una fuente de discursos, una fuente semeia y un relato de la pasión. Por otro lado, en relación con la historia de la redacción, Bultmann sostiene que el evangelista habría escrito el evangelio tomando tradiciones y fuentes que encontró, su obra habría sido completada por un «redacción eclesial», desde este punto de vista su propuesta mezcla elementos tanto desde el punto de vista genético como de tradiciones orales.

Bultmann discrimina tanto la teología como el estilo de la fuente semeía y el del evangelista en base a que identifica a éste con el estilo de los discursos ${ }^{2}$. Bultmann introduce el texto de 1, 19-34 señalando que se trata de la interpolación de un redactor, en cambio el texto base proviene del evangelista. Bultmann considera que para «él (evangelista) es característico que Jesús es 'el profeta' (ver 6, 14; 4, 19.44; 7, 52; 9, 17) y

2 Cfr. R. Bultmann: Das Evangelium des Johannes. Vandenhoeck \& Ruprecht, Göttingen 195916, 68. 
que el título el profeta y el Cristo están coordinados» ${ }^{3}$. No obstante considera que posee un valor preponderante el evangelio. Bultmann postulará la existencia de una fuente semeia, la cual describe a Jesús como un theios aner. Esta fuente comenzaría en 1, 35. Señala Bultmann a pie de página que «el Jesús joánico no será presentado como profeta sino como

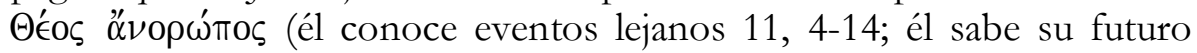
destino 2, 19.21; 3, 14; 6, 64; 13, 1.38; 18, 4; 19, 28, como el de los otros $13,36 ; 16,2)$ cuyo admirable saber no remite ni corresponde a un don de Dios, sino sobre su personal divinidad» ${ }^{4}$. Y añade «la idea de la omnisciencia pertenece también la característica mitológica (auspragung) de la idea de la revelación, y su servicio es colocado en el interior del evangelio de Juan en función del motivo del theios anern. ${ }^{5}$. Más específicamente, Bultmann cree que la cristología joánica muestra a Jesús como emisario divino tal como lo presentan los escritos gnósticos.

En relación a los relatos de 1, 19-34, señala que el redactor ha introducido la cita de Is 40, 3 de acuerdo a la tradición sinóptica, y los vv. 33-34 son adscritos por Bultmann al evangelista. En relación al v. 21, el relato juega con el presupuesto de una figura mesiánica como Elías (6, 4; $7,40)$. Señala Bultmann en relación al v. 21 que «la espera de un profeta en el judaísmo no es atestiguada» más bien corresponde a una expectativa cristiana, e indica «quizás está pensada en una figura, la que en principio es atestiguada no en el judaísmo ortodoxo, sino al contrario en círculos herético-sincretistas» ${ }^{6}$. En el v. 34 Jesús es en su persona todo lo que el Bautista ha negado: Mesías, Elías, el profeta «este es el hijo de Dios». En el siguiente texto, del primer llamado de los discípulos (1, 3551), es esencialmente una unidad propia del evangelista quien ha utilizado una fuente escrita. El autor sostiene que tal como indica 1, 3551, «Jesús se muestra como un theios antrophos...».

En resumen, pareciera que Bultmann sostiene la idea que en los materiales más antiguos pertenecen a tradiciones sueltas, a una fuente semeia o a una fuente de discursos. En lo referente a los materiales pertenecientes al ciclo del bautista, la figura de Jesús se presenta como un profeta, pero que este es modulado por el evangelista teniendo en cuenta la figura del Theios aner y del mito gnóstico del salvador. En esta primera fase de elaboración, Bultmann no habla de Grundschrift sino que,

3 Ibíd., 58. Una exposición crítica en D. M. SMYTH Jr.: Composition and Order of Fourth Gospel. Bultmann’ Literary theory, Yale University Press 1956.

4 R. Bultmann: Das Evangelium des Johannes, 71.

5 Ibíd.; J. BECKER: "Wunder und Christologie", New Testament Studies 16 (1970), 130 148.

6 R. Bultmann: Das Evangelium des Johannes, 62.

7 Ibíd., 75. 
contrariamente a los defensores de la teoría de los estratos, Bultmann piensa que la unidad del evangelio es obtenida al final de su evolución y no al comienzo. Da la impresión en todo esto, que el redactor eclesiástico ha insertado glosas en la escatología y sacramentología del evangelista.

Uno de los primeros críticos del trabajo de Bultmann surgió de las propias filas del maestro. E. Käsemann, en su libro The Testament of Jesus, comprende el evangelio de Juan como escrito docetista ${ }^{8}$. Käsemann ve la figura de Jesús en el evangelio como la de un taumaturgo, salvador del mundo, y el ser celestial preexistente ${ }^{9}$. El mensaje de todo el evangelio es la gloria, así como lo menciona 1, 14. Käsemann en un comienzo está de acuerdo con la existencia de una fuente semeia y describe a esta como una fuente que expresa una cristología del theios aner. Las historias de milagros sirven a la cristología docetista que Käsemann cree profesar el evangelista. Para este autor la cuestión de las señales en Juan no puede ser explicado por la falta de fidelidad a la tradición. Él tomó la tradición libremente y selecciona aquel material que estaba más de acuerdo a su teología de la gloria. Otro discípulo de Bultmann, G. Bornkamm, en su artículo Zur interpretation des Johannesevangelium, señala que con seguridad se puede reconocer en la historia de milagros una tradición preformada, importantes razones hablan de «las señales de Jesús». La imagen del Cristo joánico de la tradición existente en muchos aspectos corresponde a la imagen de un Dios caminando sobre la tierra, sin embargo esto no significa que se deba responsabilizar a toda la tradición de esta cristología, "para descargar al evangelista de esto y hacer a él sólo un crítico de esta tradición» ${ }^{10}$. Bornkamm señala «los elementos de la tradición prejoánica en el evangelio tampoco son simplemente como lamentables restos de la tierra, los cuales el evangelista no ha podido expulsan» ${ }^{11}$. Más bien es necesario comprender que ambas visiones, la del

8 Cfr. E. Käsemann: The Testament of Jesus. Fortress Press, Philadelphia 1968, 24; version en castellano El Testamento de Jesús, Sígueme, Salamanca1983; E. KäsEmAnN: "Aufbau und Anliegen des johanneischen Prologs", en E. Käsemann (ed.), Exegetische Versuche und Besinnungen, Vandenhoeck \& Ruprecht, Göttingen 1970, 155-180; W. A. MEEKS: "The Man from Heaven in Johannine Sectarianism", Journal of Biblical Literature 91 (1972), 44-72. Meeks desarrolla el tema de arriba/abajo en el evangelio de Juan «in one sense what is happening in the Johannine dialogues is the combination of familiar patterns from Jewish tradition-above all the picture of the apostolic prophet, that of the heavenly Wisdom that seeks a home among men only to be rejected, and perhaps, that of the angel who beats Yahweh's name».

9 Cfr. E. KäsEMANN: El testamento de Jesús, 127.

10 G. BORNKAMM: "Zur interpretation des Johannesevangeliums. Eine auseinandersetzung mit Erst Käsemanns”, Evangelische Theologie 28 (1968), 20.

11 Ibíd. 
Jesús terrenal y la crítica hecha a esta imagen, pueden provenir de una misma raíz. Bornkamm afirma el carácter altamente dialéctico del cuarto evangelio. En directa reacción a Käsemann, sostiene Bornkamm la necesidad de «determinar con más precisión todavía el fondo religiosohistórico del cuarto evangelio» ${ }^{12}$ criticando la postura de Käsemann quien sostenía como suelo del cuarto evangelio el ambiente de «entusiasmo helenístico» ${ }^{13}$. Para G. Bornkamm hay que buscar las categorías del cuarto evangelio en «la escatología del judaísmo posterior» ${ }^{14}$. Además este autor ha realizado un interesante paralelo del tema de los emisarios divinos con el envío del paráclito, que muy probablemente se puede relacionar con los enviados divinos según lo comprendieron los grupos heterodoxos judíos.

A su vez, E. Häenchen, en Das Johannesevangelium, sostiene no un Grundschrift, pero sí un Vorlage, «un tipo de evangelio de Marcos ampliado» ${ }^{15}$. El autor afirma que la unidad literaria del cuarto evangelio no es «ninguna unidad estilística» ${ }^{16}$, y en relación con la cristología joánica, Häenchen se pregunta por el sentido que tendría que el evangelista hubiese adoptado un escrito o una tradición con una distinta teología. La tradición del evangelista depende de una tradición oral (Vorlage) que se remonta al tiempo del evangelio de $\operatorname{Marcos}^{17}$ y que presenta a Jesús como theios aner. En esta Vorlage, los milagros no son entendidos como prueba de su divinidad de Jesús sino como «señales», indicaciones de algo completamente distinto. El evangelista estaba convencido por completo de la objetividad de los milagros, presente en su Vorlage. Éste «corrige pero sin que por esto niegue la tradición del theios aner ${ }^{18}$. Piensa Häenchen que el autor del cuarto evangelio bien pudo «mejorar un evangelio escrito» lo que Bultmann nombra como semeia Quelle bien pudo haber sido este evangelio, es decir, un tipo de evangelio de Marcos ampliado. Los pedazos sinópticos presentes en el cuarto evangelio pueden provenir de este evangelio. En Johanneische

12 G. BornKAmm: "El paráclito en el evangelio de Juan", en ibíd., Estudios sobre el Nuevo Testamento. Sígueme, Salamanca 1983, 256.

13 Ibíd.

14 Ibíd.

15 E. HÄenchen: Das Johannesevangelium. Ein Kommentar, J.C.B. Mohr, Tübingen 1980, 303; Ibíd., "Aus der Literatur zum Johannesevangelium 1929-1956”, Theologische Rundschau 23/4 (1955), 295-335.

16 E. HÄENCHEN: "Johanneische probleme", Zeitschrift fur Theologie und Kirche 56 (1959), 52.

17 Ibíd., 21.

18 E. HÄENCHEN: Das Johannesevangelium, 107. 
probleme $^{19}$, Häenchen señala que el evangelista ha encontrado su Vorlage en una «forma estable» que se puede comprobar en los contactos sinópticos, el cual ha utilizado con libertad; el relato de la multiplicación de los panes $-\mathrm{y}$ en general de los milagros-, está en función de la demostración del poder divino de Jesús.

Un tanto variada es la propuesta de J. L. Martyn, History and Theology $y^{20}$, subraya dos aspectos; el primero en relación con el escrito base, el cual se refiere a un sermón y que, de modo especial, estudia, no el origen, sino que contextualiza la situación de los diversos relatos en la historia de las disputas cristológicas entre cristianos y judíos presente en los textos. El sitz im Lebem de la cristología del profeta o el Mesías como Moisés es el conflicto con las autoridades judías. Importante estudio por varios motivos: sostiene en esta obra, y en el artículo Glimpses into the History $^{21}$, la teoría de la formación por estratos del cuarto evangelio. El primer periodo, que comienza antes de la guerra judía, un primer estrato se encuentra en 1,35-49, que consiste en un primitivo sermón, el cual «debe haber estado en los orígenes de la comunidad joánica». Las aporías encontradas en este texto, Martyn las explica como el trabajo editorial del mismo evangelista ${ }^{22}$. En relación a los vv. 35-49, sostiene Martyn que con algún nivel de probabilidad estamos en presencia de un primitivo estrato como una tradición anterior al esfuerzo literario del evangelista y como una no-sinóptica forma de la perícopa. La comunidad posee una expectación mesiánica, histórica-salvífica, la cual tiene su cumplimiento en Jesús de Nazaret. Él es el profeta mosaico, el escatológico Elías, el esperado Mesías» ${ }^{23}$. A esto añade Martyn otros materiales como elementos de una narración de la pasión-resurrección y un primitivo estrato de un número de historias de milagros. El periodo medio, lo caracteriza señalando que parte del grupo es nacido como una comunidad separada por la experiencia de dos mayores traumas: la excomunión y el martirio. En el primer trauma, las autoridades introducen las birka ha Minin en el servicio de la sinagoga en función de identificar y excomulgar a estos que confiesan a Jesús como Mesías. La

19 Cfr. E. HÄENCHEN: "Johanneische probleme”, 52.

20 Cfr. J. L. MARTYN: The History and Theology in the fourth Gospel. New York 1968; versión revisada: Nashville 1979; J. L. MARTYN: The Gospel of John in Christian History. Essays for Interpreters. Paulist Press, Eugen-Oregon 1978, 9-54.

Cfr. J. L. MARTYN: "Glimpses into the History of the Johannine Community. From its Origin through the Period of Its Life in Which the Fourth Gospel was Composed", en M. de Jonge (ed.), L'evangile de Jean. Sources, rédaction, théologie, Leuven University Press, 1977, 149-175; J. AsHTON (ed.), Interpretation of John, 20.

22 Cfr. J. L. MARTYN: "Glimpses into the History", 153.

23 Ibíd., 155. 
causa de la expulsión es la incompatibilidad de la cristología alta con la confesión de un $\operatorname{Dios}^{24}$. A este periodo pertenecen los numerosos debates midrásicos presentes en el evangelio. En el segundo trauma, las autoridades no sólo son excomulgadas, sino que son llevas a juicio y ejecución como Massithin. Durante este periodo, la tradicional expectativa histórico-salvífica es ahora significativamente alterada por el modelo dualista arriba/abajo ${ }^{25}$. El Mesías viene a su mundo como el extraño venido de arriba. Siguiendo la propuesta de W. Meeks, Martyn cree que el Mesías no es otro que sofia-logos a través de quien Dios creó todo $^{26}$. El último periodo, el movimiento hacia la firme-social y teológica configuración. Establece el contexto histórico de la cristología del profeta como Moisés como respuesta al conflicto surgido entre la comunidad joánica con la sinagoga judía y establece una relación entre esta expectativa y la teoría de las señales que desarrolla el cuarto evangelio. Este último punto expresaría la idea que el profeta como Moisés realizaría nuevamente las señales realizadas por Moisés en la primera liberación (ver Gn 49, 11; Zac 9, 9; Mc 11, 7).

Esta teoría también es seguida por R. Brown ${ }^{27}$ y J. Painter ${ }^{28}$, si bien ampliada a cinco fases, quienes siguiendo la teoría de los estratos o fases la explican del siguiente modo: la fase 1 o pre-evangélica (50-80 d.C.), aunque éste no postule un Grundschrift sino tradiciones que circulan oralmente. Durante varias décadas dentro de la comunidad joánica, el material fue seleccionado y desarrollado en historias y discursos que son el modelo del cuarto evangelio. Brown de acuerdo con Martyn señala que en los orígenes del grupo joánico hay una cristología «baja» que reconoce a Jesús como mesías (Jn 1, 35). Sostiene que la cristología de la pre-existencia surgió en el segundo estadio, «Jesús habría sido interpretado según estas ideas» ${ }^{29}$. Cuyos portadores serían discípulos de Juan el Bautista. Brown critica a Martyn que no da ninguna explicación del paso de una cristología baja del Mesías, a otra alta, de la pre-

24 Cfr. M. MEnKEn: "The Christology of the Fourth Gospel: A survey of recent research", en M. de Boer (ed.), From Jesus to John. Essays on Jesus and New Testament Christology in Honour of Marinus de Jonge, 295.

25 Cfr. J. L. MARTYN: "Glimpses into the History”, 155.

26 Ibíd., 165.

27 Cfr. R. Brown: Comentario del evangelio según san Juan. Cristiandad, Madrid 1970; R. Brown: La comunidad del discipulo amado. Salamanca 1991; R. BROWN: An Introduction to New Testament. Paulist Press, New York 1994, 196-213; SCHNACKENBurG: Evangelio, 1314. El autor sostiene que Brown no fundamenta suficientemente tal teoría.

28 Cfr. J. PAINTER: The Quest for the Messiah. History, Literature and Theology of the Johannine Community. T\&T Clark, Scotland 1991, 45.

29 R. BROWN: La comunidad del discípulo amado, 32. 
existencia. A Juicio de Brown, este paso de una a otra se explica por la integración a la comunidad joánica de grupos samaritanos (Jn 4) portadores de una cristología del profeta escatológico como Moisés (Dt $18,15.18)^{30}$, y de una concepción anti-templo, en quienes sería muy lógico y normal referirse a los adversarios como los «judíos». A juicio de Brown, Juan habría mantenido la terminología de una cristología más baja y más antigua atribuyéndole nuevos significados ${ }^{31}$. La segunda fase corresponde a la época en que los relatos se transmiten oralmente. Durante este período también se escribe $1 \mathrm{Jn}$. La expulsión de la sinagoga ya ha tenido lugar, pero quedan las huellas de este conflicto. La tercera fase, es la primera redacción del cuarto evangelio. El material fue organizado por alguien (el evangelista) en forma escrita, probablemente en griego. Este fue el evangelio base formado por signos milagrosos, y discursos explicatorios que tenemos hoy. Estos escritos primitivos están interesados en varios títulos judíos, que pueden ser atribuidos a Jesús: cordero de Dios (1,36), rabbi (1,38), Messiah (1,41). Durante esta primitiva etapa $(2$ y 3$)$ la comunidad es probablemente judía y todavía capaz de alabar a Dios en la sinagoga. La fase cuarta, es la segunda edición del cuarto evangelio. Un segundo ensayo es escrito (por el mismo evangelista), quizás por encontrar nuevos problemas que han surgido en la comunidad —en lugar de Juan Bautista y sus discípulos, la comunidad joánica no es bienvenida en la sinagoga, la admisión de samaritanos y gentiles en la comunidad, la ruptura de los cristianos con la sinagoga, etc. Este último conflicto se aprecia por el uso retórico del apelativo «judíos» en las narraciones. Una última fase, después de la muerte del discípulo amado, una edición final por alguien que puede no haber sido el evangelista pero que fue un discípulo cercano, el capítulo 21 pertenece a esta etapa. Señala R. Brown que el defecto principal de estas teorías de la redacción consiste en que caen en la tentación de querer reconstruir demasiado exactamente la historia de la redacción. La propuesta de R. Brown mantiene conscientemente el orden actual del evangelio, éste es asumido como un riesgo, debido a que según lo señala el autor el reordenamiento corre un riesgo mayor.

En su cristología del Nuevo Testamento, O. Cullmann sitúa esta esperanza mesiánica en el contexto del desarrollo de la profecía en el Judaísmo tardío. Señala Cullmann que «(...) lo mismo que todos los profetas han anunciado la misma verdad divina, hubo también uno y el mismo profeta, el cual se encarnó en forma sucesiva en diferentes hombres. Así está presente la visión, está en base siempre a la aparición

$\begin{array}{ll}30 & \text { Ibíd., } 44 . \\ 31 & \text { Ibíd., } 52 .\end{array}$

VERITAS, $\mathrm{N}^{\circ} 23$ (Septiembre 2010) 
del mismo profeta; él ha tomado cada vez una distinta forma» ${ }^{32}$. Este presupuesto está a la base de una serie de textos neotestamentarios y a partir de ese se comprende la pregunta dirigida a Jesús en Jn 1, 21. O. Cullmann, en Johannine circle, critica la solución de R. Brown «to go too far» y sostiene fundamentalmente dos momentos, el primero, el evangelista hizo uso de tradiciones, no fuentes, de diverso origen y desarrolló la obra tal como la conocemos hoy. En un momento posterior un redactor o un grupo de redactores revisaron y completaron la obra. Cullmann advierte contra el intento de diseccionar diversos «estratos» o «fuentes» ya que la lógica moderna y los modos de pensar del hombre moderno no son necesariamente los mismos que estos del cristianismo del siglo I, de tal modo que más que construir una idea sobre otra, el primitivo cristianismo debió más bien presentar la misma verdad desde diferentes perspectivas. Cullmann estudia la relación entre la comunidad joánica (ver Jn 4) y el grupo helenista de Hch 7 encontrando que la cristología de ambos grupos está basada en la idea de que Moisés es el prototipo de Jesús según el texto de Dt 18, 15.18.

\subsection{El recurso a un Grundschrift o Semeia Quelle}

Diversos autores explican esta teoría por el recurso a un Grundschrift. El primero en formular dicha teoría fue J. Wellhausen, en Erweiterungen und Änderungen in vierten Evangelium, quien distingue un estrato (Grundschrift), es decir, un evangelio anónimo formado de relatos de milagros $^{33}$. Otro autor importante que se mueve en esta línea es W. Wilkens $^{34}$. Éste autor entiende su propuesta como resultado de una

32 O. Cullmann: Die Christologie des neuen Testaments. J. C. Mohr (P. Siebeck), Tübingen, $1958^{2}, 17$.

33 Sobre la línea de Wellhausen se colocan E. Schwarz (1907-1908), F. Spitta (1910), E. Hirsch (1936). Hirsch distingue un evangelio primitivo compuesto sobre la base de varias fuentes tradicionales y un redactor que añade y hace varios comentarios al texto. W. Bacon (1910 y 1936) propone tres fases o etapas en la génesis del cuarto evangelio: un relato de discursos y señales, ligado a la fiesta hebraica; la elaboración del añadido del prólogo y de la pasión, muerte y resurrección es precedido de Jn 15-16; la redacción final, y Jn 13-14.21 fue armonizado con los sinópticos.

34 Cfr. W. WILCKENS: Enstehungsgeschichte zum johannesevangeliums, evangelischer Verlag Ag, Zollikon, Switzerland 1958. La recensión J. RoBINSON: "Recent research in the Fourth Gospel”, Journal of Biblical Literature LXXVIII (1959), 242-252; H. THYEN: "Aus der Literatur zum Johannesevangelium”, Theologische Rundschan 39/4 (1974), 308s. Un trabajo posterior de Wilckens, Zeichern und Werke. Ein Beitrag zur Theologie des 4. Evangeliums in Erzälungs-und redestoff (AThANT 55) Zürich 1969; la recensión de Fortna: "Wilhem Wilkens's Further Contribution to Johannine Studies", Journal of Biblical 
crítica literaria que sigue los pasos de la propuesta por Wellhausen y propone en la introducción de su libro que en «la crítica literaria al cuarto evangelio no solo tiene lugar una crítica de las fuentes sino también una historia de su formación» ${ }^{35}$. En este contexto la crítica de las fuentes representa un caso especial ${ }^{36}$. Al considerar la posición de Bultmann acerca de la existencia de fuentes, señala que «no es seguro, que el evangelista haya tenido ante si fuentes escritas» ${ }^{37}$. Wilkens cree que «la historia de la formación del cuarto evangelio ha transcurrido bajo la mano de una y la misma persona». Este proceso de formación consiste en una ampliación de un escrito base (Ausbau eines johanneischen Grundschrift), diferenciado por tres fases en la historia de la formación. El evangelista mismo en un principio escribió un Grundevangelium, tipo sinóptico; un evangelio de base o evangelio de señales, el cual contenía solo narraciones. Una primera sección de cuatro signos en galilea; otras señales realizadas en Jerusalén y un relato de la pasión. Esto muestra que para Wilckens el Grundevangelium fue un Zeichenevangelium, el cual tiene como cristología demostrar que Jesús es el mesías hijo de Dios. Por esto, está interesado en demostrar que este escrito base comienza con el testimonio del evangelista en $1,19-34^{38}$ y termina con el texto de 20,30 . Wilckens inicia su análisis por 20,30 s señalando que este versículo trata solamente de las obras de Jesús bajo el punto de vista de las señales para que el lector crea que Jesús es el Cristo, el hijo de Dios. Los discursos no son señales; en 12, 3 ocurre lo mismo, sólo se habla de señales y no de discursos. Con esto se afirma que los discursos no estuvieron unidos a las señales originariamente. El discurso del pan de vida ignora la historia de la multiplicación $(6,30)$; y lo mismo puede decirse del discurso del juicio $(5$, 17), el cual, en opinión de Wilckens, no está «unido orgánicamente a la primera señal en Jerusalén» ${ }^{39}$. Similar opinión afirma el autor sobre el cap. 10. Sostiene que una observación crítica del cuarto evangelio conduce desde varios lados a suponer un originario Grundevangelium joánico que una y otra vez ha sido completado y ampliado. El evangelio de las señales forma el fundamento, el cual fue completado por los discursos.

El cap. 8 no muestra ninguna conclusión. El discurso del buen pastor cap. 10 no está unido orgánicamente con la sanación del ciego de

Literature LXXXIX (1970), 457-462; C. DEKKER: "Grundschrift und redaktion im Johannesevangelium”, New Testament Studies 13/1 (1966), 66-80.

35 W. WILCKENs: Enstehungsgeschichte, XI.

36 Ibíd.

37 Ibíd., 6.

38 Ibíd., 33.

39 Ibíd., 31. 
nacimiento (cap.9). Es importante notar el criterio que sirve a Wilckens para discriminar entre un escrito y otro. Existe una falta de unidad orgánica entre uno y otro, el Grundschrift es narrativo en cambio las ampliaciones fueron realizadas mediante discursos. Éstos y las señales no muestran una particular «relación de firmeza». El relato del 1, 19-34 pertenece al Grundschrift y describe los hechos ocurridos en la primera jornada, los versículos incluidos son: 1, 6-7a.c.19-21.25-26.27.31.3334.28.35-42.43a.b.

Para otros autores, como M. E. Boismard-A. Lamouille ${ }^{40}$, esta hipótesis es altamente compleja. El evangelio de Juan sería desarrollado en cuatro etapas sucesivas pero al interior de una misma «escuela joánica»: un evangelio arcaico (Juan $\mathrm{I}=$ Doc C) que va de Juan Bautista al relato de la aparición del resucitado, en el cual son relatados cinco milagros galileos «señales», sin discursos. En este escrito se presenta una cristología de tipo mosaico-profética ${ }^{41}$. En esta fase, el evangelio primitivo es ampliado por un autor que llama Jn II y que compone su primera redacción evangélica (Jn II, A) igualmente en Palestina. El mismo autor hace una segunda edición (Jn II, B) de este evangelio palestinense, lo cierra y transforma el material, añade material proveniente de los evangelios sinópticos. Un tercer autor (Jn III), integra en el evangelio (Jn II, B) los pasajes paralelos de Jn II, A y algunas logia del ambiente joánico. En esta fase y de atribuirse al orden actual de los capítulos quinto y sexto, invertido respecto del original, este autor introduce algunas glosas teológicas y tiende a esfumar la polémica anti judaica típica del estado de Jn II-B. El documento C es datado alrededor de los años 50, Jn II, A en los años 60-65, Jn II, B una treintena de años más tarde y Jn II en los primeros años del siglo II. M. Boismard habla por consiguiente de tres redactores y cuatro etapas.

En relato de Jn 1, 19-36 está formado por dos relatos paralelos X e $\mathrm{Y}$, fusionados hábilmente por el redactor ${ }^{42}$. En donde el texto $\mathrm{Y}$ es una relectura del texto $\mathrm{X}$. En relación al vv. 31-32 pertenece al relato X, en el primer relato Dios actúa en el misterio, en el segundo en cambio Dios actúa de una manera mucho más ostensible: él revela al Bautista que el

40 Cfr. M. E. Boismard: Moses or Jesus. An Essay in Johannine Christology. Leuven University Press, Leuven 1993; M. E. BoISMARD: "Les tradition Johanniques", Revue Biblique LXX (1963), 5-42; M. E. BOISMARD: "L'evolution du theme eschatologique dans les traditions johanniques", Revue Biblique 4 (1961), 507-524; F. NEYRINCK: "L'évangile de Jean. Examen critique du commentaire de M.-É. Boismard et A. Lamouille", Ephemerides Theologicae lovanienses LIII (1977), 363-478.

41 Cfr. M. E. BOISMARD: Moses or Jesus.

42 Cfr. M. E. BoISMARD: "Les tradition Johanniques Concertant Le Baptiste", Revue Biblique LXX (1996), 9. 
Espíritu debe designar al Mesías. En el primer texto, «en definitiva el texto $\mathrm{Y}$ explicita esto que era implícito en el texto $\mathrm{X} \gg{ }^{43}$. Bultmann

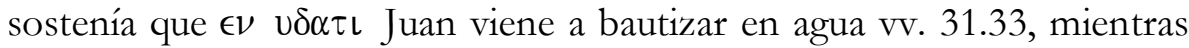
Jesús bautiza el fuego. Boismard sostiene que estilo es joánico y tiene su paralelo en Jn 9, 37 y que «evoca evidentemente Is 11, 2; 42, 1» ${ }^{44}$. Jesús es el Mesías anunciado por el profeta Isaías. Para Boismard la fórmula «este es el verdadero profeta» y «este es el Cristo» (ver 6, 14; 7,41.52; 11, 27) son paralelas. Lo mismo vale para el episodio de la embajada de Jerusalén y Juan el bautista que presenta a Jesús el cordero de Dios ${ }^{45}$. Para Boismard el texto de Jn 1, 45-49 supone como background el tema de Jesús como profeta, a diferencia de Bultmann y otros después de él que ven en conocimiento sobrenatural de Jesús, un signo de la imagen de un Theos anthroopos. Boismard señala que «tal conocimiento sobrenatural es la característica del profeta (2 Sam 12, 1-7)» ${ }^{46}$. Juan II toma de su fuente el tema de Jesús como el profeta similar a Moisés, pero lo enriquece con nuevos elementos: Jesús es mucho más que Moisés. Desde un punto de vista metodológico, Boismard utiliza $1 \mathrm{Jn}$ para realizar su trabajo de comprobación del estilo joánico, constatando en el texto de 1, 19-34 la presencia del estilo de la $1 \mathrm{Jn}(1 \mathrm{Jn} 5,11 ; 1,8-10)$ en este relato ${ }^{47}$.

Para Boismard el capítulo 3 es una relectura del capítulo 12 y los vv. 19b-21 al parecer están fuertemente influenciados por una «cierta concepción qumránica del juicio» ${ }^{48}$. Boismard encuentra dos ediciones diferentes de un mismo discurso: 12, 46-30; y 3, 16-19a; 5, 30b-32.37; 8, 14-18; 5, 26-30a y 5, 19-25. Los versículos 19-25 serían una relectura de los vv. 26-30. Algo similar dice de Jn 5, 19-25, que sería una relectura de Jn 5, 26-30, y que representa un estado posterior de desarrollo de la tradición joánica ${ }^{49}$. De acuerdo a esto señala Boismard que «el evangelio de Juan en su forma actual no constituye un todo homogéneo. Es el compuesto de couches redaccionales de épocas diferentes perceptible sobre todo gracias a los dobletes que contiene $\rangle^{50}$. Estos dobletes no son

\footnotetext{
43 M. E. BOISMARD: "Les tradition Johanniques", 22.

44 Ibíd., 11.

45 Cfr. M. E. BOISMARD: Moses or Jesus, 29.

46 Ibíd., 27; O. BETz: “Aus Nazaret kann etwas Gut kommen?”, en O. Betz (ed.),

Das Problem des Wunders bei Flavius Josephus Josephus Studien. Untersuchungen zu Josephus dem antiken Judentum und dem Neuen Testaments, Vandenhoeck \& Ruprecht, Göttingen 1974). Sostiene Betz que de acuerdo a los textos de Qumrán, uno de los principales dones del Espíritu otorgados al Mesías es el don del conocimiento.

47 Cfr. M. E. Boismard: "Les tradition Johanniques", 24.

48 M. E. BOISMARD: Evolution du Thème eschatologique, 515.

49 Ibíd., 519.

50 Ibíd., 523.
} 
tradiciones independientes unas de otras sino que representas «relecturas».

Este autor recalca el papel de Moisés en la cristología joánica Boismard habla de «evolution of christology». Para el Documento C, Jesús es presentado como el profeta similar a Moisés (1, 19-21.26.3132.29; 43-49). Juan II desarrolla el tema agregando el episodio de la multiplicación de los panes $6,1-15$, que desarrolla y corrige la cristología del profeta mosaico; en él se remite a los textos de 2 Re 4, 42-44 y en la conclusión a Dt 18, 18. El autor de Juan II es el que por primera vez «aplica el título en positivo sentido a Jesús» ${ }^{51}$. El título tiene un sabor samaritano que incluye cierto desprecio por los judíos, esto. Juan II, A lo corrige añadiendo el título Cristo. Para Boismard, Juan II, A está en el origen de la doble confesión de 7, 40-42. En relación con la escatología se constata una evolución de la escatología análoga al pensamiento de Pablo. La escatología futura es análoga a la que encontramos en los sinópticos mientras que la escatología realizada en la referida a la vida de la comunidad de la Iglesia post-pascual.

Según algunos autores el recurso a un escrito fundamental se identifica como la teoría de la semeia Quelle, como es el caso de R. Nordsieck ${ }^{52}$ y G. Richter ${ }^{53}$. Estos autores llaman a este Grundschrift judeocristiano: Grundevangelium o Zeichenevangelium, el redactor, el cual es identificado con el evangelista, hace una discusión crítica y una negación de la cristología del profeta mosaico, entendido en sentido humanonacionalista ${ }^{54}$, de este Grundevangelium (Ablebnung ihrer Christologie). Para una serie de autores que defienden esta hipótesis como R. Fortna, P.

51 M. E. BOISMARD: Moses or Jesus, 129.

52 Cfr. R. NoRDSIECK: Johannes. zur frage nach Verfasser und Enstehung des vierten Evangeliums. Ein neuer Versuch. Neukirche, Vluyn 1998, 75-80.

53 La producción de este autor se desarrolla desde el año 1963 a 1977; G. RicHTER: Studien zum Johannesevangelium, Verlag Fr. Pustet Regensburg, 1977, 149-198; G. RiCHTER: "Die Fleischwerdung des Logos im Johannesevangelium", Novum Testamentum 14/1 (1972), 269; id, "Der Vater und Gott Jesu und seiner Bruder in Joh 20,17. Ein Beitrag zur Christologie des Johannesevangeliums", Münchener Theologische Zeitschrift 24/2 (1973), 95-114; id., "Zum sogenannten Taufetext Joh 3,5”, Münchener Theologische Zeitschrift 26/2 (1975), 101-125; id, "Zur sogenannten Semeia-Quelle des Johannesevangeliums”, Münchener Theologische Zeitschrift 25 (1974) 64-73; id., "Blut und Wasser aus durchbohrten Seite Jesu”, Münchener Theologische Zeitschrift 21/1 (1970), 1-21; id., "Grundschrift und redaktion im Johannesevangelium", New Testament Studies 13 (1966), 66-80.

54 Para una aproximación al tema del 'hombre' como ángel, cfr. C. CARBULLANCA NúÑ̃E: "Orígenes de la cristología del cuarto evangelio. Un estudio a partir de la tradición de 11QMelquisedec", Teología y Vida, vol. 1, n³ (2009), 567-597; id., "La entronización del hombre en tradiciones apocalípticas judías", Estudos de Religiao, 23 (2009) 36, 153-178. 
Borgen, y R. Kysar, por ejemplo, el texto Jn 6, 1-15, refleja una tipología mosaica que muestra una insuficiente aproximación al misterio de Cristo. Para Fortna la tipología mosaica es aplicada por la fuente semeia, pero el evangelista ha cambiado esta imagen, señalando algunas objeciones. La designación de Jesús como profeta como Moisés es ambigua como todo título mesiánico, puede ser entendido políticamente o «como 4E diría un modo terreno». De modo semejante, G. Richter señala que el profeta escatológico sería entendido en término humanos, en cambio en los discursos se presentaría en términos divinos. Para Richter: «la visión que el Mesías sólo es hombre está completamente de acuerdo con Dt 18,15.18», en cambio para el evangelista, Jesús ha bajado desde los cielos. Esta corrección consiste en una demostración y defensa del origen divino y de la filiación divina de Jesús. Un redactor posterior el cual llama «redactor

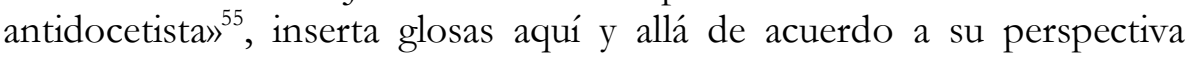
teológica. Por tanto Richter discrimina tres autores, el autor del Grundschrift, el cual comprende a Jesús como Mesías profeta prometido sobre la base de señales y otros hechos mesiánicos. El primer redactor (evangelista), critica la cristología del Grundschrift y propone la cristología del origen divino y la divinidad de Jesús y finalmente un redactor antidocetista, del cual provienen glosas y añadidos parenéticos, en este caso Richter discrimina uno de otro por los contenidos teológicos.

En el artículo titulado Zur den Tauferzäblungen Mk 1, 9-11 und John 1,32-34, Richter se pregunta en relación al pasaje perteneciente al Grundschrift de Jn 1, 32-34, ¿cuál es la específica imagen del mesías en este episodio? En este relato aparece citado el texto de Is 42, 1 que habla del «elegido de Dios», es importante esta designación ya que el término del «elegido de Dios» como característica del mesías aparece en NT sólo aquí: «el Grundscrift compara a Jesús con el siervo del deuteroIsaías» ${ }^{56}$ (Is $42,1)$. Richter comprende esto, no sobre el AT sino sobre el judaísmo contemporáneo. En efecto, la designación de «elegido de Dios» para designar al mesías se encuentra en la apocalíptica judía contemporánea al Jesús histórico. La específica imagen del mesías, cuyo rasgo es el Grundschrift, describe o busca señalar que «es el Profeta como Moisés, el profeta prometido por Moisés (Dt 18, 15.18)» ${ }^{57}$.

En esta misma línea debemos mencionar a R. Fortna, The Gospel of Signs, quien pretende reconstruir los textos de la fuente de los signos. Para lo cual enumera tres criterios: ideológico, estilístico y contextual. De estos tres criterios, el autor desestima los dos primeros y prioriza el

\footnotetext{
55 G. RICHTER: Studien zum Johannesevangelium, 149-198.

56 G. RICHTER: "Grundschrift und redaktion im Johannesevangelium", 54.

57 Ibíd.
} 
tercero. Nosotros subrayaremos que el primer criterio es esencial para discriminar los aspectos iniciales de la cristología joánica. Para el autor, el principal título cristológico en el evangelio de Juan es el título Mesías, sin embargo, hace notar Fortna que existe poquísima evidencia que refleje la expectativa de que el Mesías realizara milagros. Una posible respuesta al silogismo: Jesús hizo milagros, luego Jesús es el Mesías, es la afirmación que Jesús es el profeta escatológico como Moisés (cfr. 4, 19; 6, 14) que como el antitipo de Moisés debía presentar una serie de milagros para acreditarse como tal. Fortna no está convencido de que la figura de Moisés esté en la base de los relatos de milagros, más bien postula que los milagros de Jesús que presenta el cuarto evangelio están diseñados sobre el modelo de milagros realizados por diversos héroes del Antiguo Testamento como Elías, Eliseo e incluso José. Estos primitivos héroes fueron considerados en algunos círculos judíos próximos al helenismo como hombres divinos. Por esto, Juan se esfuerza en base a esta relación por demostrar que Jesús es un theios aner. Por consiguiente, Fortna sostiene que la expectativa del profeta escatológico está ya presente en esta fuente pero que estaría en función de su cristología del theios aner.

Fortna enumera diversos textos del evangelio que presentan una relación con el profeta escatológico en la figura de Elías (ver Jn 4, 50; 6, 9; 9, 7), en relación a Moisés sostiene Fortna que al menos los textos de Jn $6,14 \mathrm{~s}$ es necesario referirlo a la fuente, no obstante, que en general sostiene que es preciso considerar esta relación (Moisés-Jesús) como redacción del evangelista ${ }^{58}$. En relación al texto de 1, 19-34, señala Fortna que pertenece a una tradición pre-joánica, específicamente a «tradiciones del bautista». Los vv. 29-31, son una creación del evangelista «imitando elementos pre-joánicos como joanicos» ${ }^{59}$, y los vv. 32-34, el v. 32 refleja la mano de Juan y el v. 33 es una construcción joánica; y el giro «el visto y he testimoniado» parece una reiteración joánica, la sección está caracteriza por dobletes que son explicables como «expansiones teológicas». En el capítulo cuatro, Fortna reconstruye los pasajes de la fuente (4, 4.5.6.7.9.16.17.18.19.25.26.28.29.30.40.42), en relación a 6, 6771 él piensa que el evangelista utilizó una forma de la historia pre-joánica y señala «yo creo que Juan usó una distintiva tradición aquí, pero que ésta ha sido considerablemente reescrita por él». Fortna piensa que el relato de 6,1-25 estaba en la fuente semeia y la tipología mosaica pertenece a

58 Cfr. R. FORTNA: The Gospel of Signs. Cambridge University Press, Cambridge 1970, 232; id., The Fourth Gospel and its Predecessor. Fortress Press, Philadelphia 1988. Para una evaluación de esta teoría, cfr. G. VAN BELLE: "The signs Source in the Fourth Gospel. Historical survey and critical evaluation of the semeia hypothesis", BEThL CXVI, Leuven, 1994.

59 R. FORTNA: The Gospel of Signs, 176. 
ella. La aclamación de Jesús como profeta es auténtica como una respuesta al milagro, pero ahora es nada menos que expresión del malentendido de la muchedumbre. La tipología mosaica es aplicada por la fuente, pero el evangelista cambia esto, señalando algunas objeciones. La designación de Jesús como profeta, como Moisés, es ambigua como todo título mesiánico, puede ser entendido políticamente o «como $4 \mathrm{E}$ diría un modo terreno» ${ }^{60}$, esto es subrayado por la inserción del v. 15. Sin la tipología mosaica difícilmente el evangelista podría haber hecho estas afirmaciones. El capítulo 21 lo considera como un apéndice post-juánico.

Otro autor que continúa la línea de R. Fortna en cuanto al desarrollo de semeia Quelle para interpretar la cristología del cuarto evangelio, es W. $\mathrm{Nicol}^{61}$, quien sigue la perspectiva abierta por E. Schweizer y E. Ruckstuhl en vista de analizar los diversos estratos presentes en el cuarto evangelio de acuerdo a los siguientes criterios: de forma, estilo y aporías existentes en los relatos. Para nuestra investigación es relevante que Nicol sostenga que la cristología de la fuente semeia está basada en la triada: Milagros-Profeta escatológico-Mesías. Es decir, siguiendo la misma línea que R. Fortna, pero sosteniendo que Fortna «ha ido demasiado lejos» en su reconstrucción de una fuente semeia ${ }^{62}$. Nicol piensa que «los milagros son conectados al Mesías vía el profeta» ${ }^{63}$. Además Nicol señala que la relación entre la fuente de los signos y el resto del evangelio es de integración, solución que está de acuerdo con nuestra hipótesis. En efecto, Nicol sostiene que Juan adopta la teología de la fuente de signos. Ahora bien, existe un elemento sorprendente en el evangelio de Juan. La fuente de los signos y Juan contienen las más claras referencias al profeta escatológico, pero paradójicamente el evangelio tiene como título cristológico principal a Jesús como el Mesías, no al profeta escatológico. Esto se explica porque para la expectativa judía el enviado final debía ser legitimado mediante signos. Y concluye Nicol que

60 R. FORTNA: The Fourth Gospel, 88; P. BORGEN: "John 6: Tradition, Interpretation and Composition", en M. C. de Boer, ed., From Jesus to John. Essays on Jesus and New Testament Christology in Honour of martinus de Jonge, JSOT Press, Scheffield 1993, 278-279. Borgen también contrapone la relación terrestre-celestial «then these verses are to be seen precisely as a restatement of the crowd's view that the feeding miracle correspond to the manna miracle and thus legitimated Jesus as a prophet like Jesus (vv.14-15). In their view, since Jesus had already legitimated himself as a prophet by the feeding miracle, they now needed another sign which would demonstrate that he was one sent by the Father, that is, the son of man...(vv.27-29)»; R. KYSAR: John Maverick Gospel, Wesminter J. Knox Press, London 1976², 51-52.

61 Cfr. W. NicOL: The semeia in the Fourth Gospel. Tradition and Redaction. E. J. Brill, Leiden 1972.

62 Ibíd., 5.

63 Ibíd., 62. 
aunque la esperanza de un profeta escatológico como Elías o Moisés y el Mesías no se identifican, la posibilidad de tal identificación es evidente al judaísmo, pues se piensa que el tiempo de la primera liberación y la persona de Moisés fueron comprendidos tipológicamente a la del tiempo mesiánico y la Mesías mismo.

De manera similar, J. Becker acepta la semeia Quelle en Das evangelium nach jobannes, e identifica la cristología de esta fuente con la del profeta de los últimos tiempos. Posteriormente, según esta reflexión cristológica, el evangelio se habría ampliado por obra del evangelista a una cristología «alta» de la pre-existencia o del enviado la cual habría reformulado estos temas. J. Becker sostiene en Wunder und Christologie $e^{64}$ que la semeia Quelle está constituida por un Grundstock, el cual en su primera parte describe la actividad de Galilea comenzando con 1, 19s. y continúa con la llamada de los discípulos en 1, 35s., las bodas de Caná, la sanación de la hija del rey, la multiplicación de los panes y la caminata de Jesús en el mar pertenecen a este mismo período. A este mismo Grundstuck pertenece el diálogo con la samaritana. Becker se pregunta por los criterios para distinguir el material de la semeia Quelle y enumera: el dualismo joánico no tiene ningún lugar en la fuente semeia; el Jesús de la fuente semeia nunca habla en el estilo de los discursos de revelación; se busca inútilmente afirmaciones escatológicas en la fuente semeia, o bien la presencia del Hijo de Dios como escatología-crisis presente ha entendido o se puede reconocer una escatología presentista en la fuente semeia; la cristología de la fuente semeia está en general interesada en el típico esquema joánico del camino, como es más claro en Jn 16, 28.

\subsection{Soluciones híbridas}

En este contexto de soluciones a la unidad literaria y teológica del cuarto evangelio, el comentario al evangelio de Juan de R. Schnackenburg en Das Johannesevangelium, pudiera clasificarse como una solución hibrida. La razón está en que para este autor, el evangelio de Juan no se ha organizado sobre estratos literarios diferentes e independientes el cual luego ha sido reunido por un redactor(es), sino que esencialmente es la obra de un evangelista, el cual se apoya en múltiples tradiciones que crecen y maduran lentamente (auf mancherlei Tradition stütre und sein Ev langsam wachsen und reifen liess) ${ }^{65}$, sin tener una conclusión final. Sin embargo,

64 Cfr. J. BECKER: "Wunder und Christologie", New Testament Studies 16 (1970)2, 135.

65 Cfr. R. Schnackenburg: Das Johannesevangelium I-IV, Verlag Herder, Freiburg 1979, 59 . 
admite tres etapas ${ }^{66}:$ materiales existentes-la obra del evangelista-redactor final. El autor afirma que probablemente se puede afirmar la existencia de una fuente escrita de signos. El autor acepta además, con algún grado de confianza la existencia de un Grundschrift o un juan. Grund-evangelium, el cual fue un material de tradiciones independientes que tuvo a su disposición. Por otra parte, adjudica a la cuenta de la redacción del redactor final el capítulo 21, además de glosas y añadidos. El autor sostiene que en la apocalíptica judía existe la idea del ascenso de figuras como Enoch, Elías, Isaías y Baruc pero la correspondiente idea de un descenso falta (...den Gedanken des Auftiegs [ascensio] reich zur Entfaltung... aber der entsprechende Gedanke des Abstiegs' fehlt). Reconoce, no obstante, que existen otras tradiciones sobre la sabiduría, en donde ésta desciende a la tierra. En relación con la cristología, Schnackenburg sostiene que el título predilecto del cuarto evangelio es «Cristo». Además señala que el término

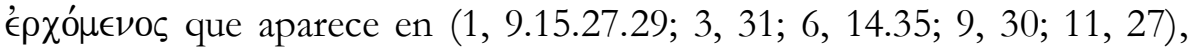
está referido al profeta escatológico y procede del evangelista que se apoya en tradiciones judías: «El evangelista está fuertemente interesado en el título mesiánico 'el profeta'» (ver Jn 6, 14.35; 11, 27; 12, 13) ${ }^{67}$. Esto lleva a suponer que, de acuerdo a Schnackenburg, este material está asociado a la cristología de la pre-existencia, argumento que nosotros también afirmaremos a partir del estudio de 11QMelq. En esta misma perspectiva híbrida, H. Thyen defiende una posición similar a la de Schnackenburg. Para este autor, en relación al texto de Jn 13, señala que «las soldaduras literarias muestran sin excepción no el uso de fuentes heterogéneas sino la crítica reinterpretación de un bomogéneo Grundschrift por un redactor ${ }^{68}$, lo mismo que en relación a Jn 21; para este investigador no se trata de una interpolación en una fuente escrita, sino ampliación de una tradición de la cena o del discípulo amado en la que el redactor ha introducido glosas y añadidos. Para H. Thyen el relato de Jn 1, 19-351 señala que él pensaba que el v. 43 era una interpolación y señalaba que «el autor de Jn 21 (...) había interpolado el sinóptico verso 43». El responsable de este verso no es el autor de un cualquier estrato sino que el propio evangelista. Thyen cambia de opinión y afirma que con propiedad se debe hablar como editor al redactor del capítulo 21. En un comienzo, Thyen era de la idea que el cuarto evangelio era independiente de la tradición sinóptica, donde sólo el redactor eclesiástico conocía esta tradición; pero por influjo de los trabajos de F. Neirynck y M. Sabbe, llegó a la convicción de que «no sólo el presunto redactor eclesiástico,

\footnotetext{
66 Ibíd., 48.

67 Ibíd., 24-25.

68 Ibíd.
} 
sino que el mismo evangelista conoció los evangelios sinópticos» ${ }^{69}$. Thyen no sigue la teoría de las fuentes ni la de teoría de los estratos, señalando al respecto: «a mí me parece que es mucho más probable que Juan, no sólo conoció fuera de la Biblia judía, tradiciones anónimas, si es posible sólo oralmente transmitidas, semejantes a la de los sinópticos, las que ha utilizado como fuentes; especialmente juega intertextualmente con el texto transmitido en su forma redaccional veterotestamentaria lo mismo que con los evangelios sinópticos» ${ }^{70}$. De esta manera, los evangelios sinópticos son entendidos por Thyen como el pretexto y el propio evangelio dentro de la teoría de la intertextualidad.

Para Thyen la cristología joánica no está basada en la idea del theios aner, sino que en el sobrenatural conocimiento de Jesús (ver Jn 1, 3.42.47; $4,16 s$ se explican a partir de la «indivisible unidad del Padre y el Hijo» ${ }^{71}$. Esto también se aprecia en el pasaje del buen pastor que «conoce a sus ovejas» $(10,3.14 .27)$ y en los numerosos comentarios del narrador y con la introducción de la escena del discípulo amado $(13,23 ; 1,18)$. H. Thyen comprende el evangelio de Juan como un texto desde un punto de vista literario como «altamente poético» y busca interpretarlo siempre como un todo no reducible a sus partes. No obstante esto, el autor sostiene la existencia de un Grundschrift ${ }^{2}$. Así, Thyen diferencia al autor del Grundschrift respecto del autor del capítulo 21, al cual Thyen llama el evangelista $^{73}$. Con un alto grado de seguridad se puede afirmar que el autor del Jn 21 y el editor de nuestro evangelio de Juan ha reelaborado una Vorlage escrita por toda clase de cambios de lugar en el texto, así como por numerosas re-interpretaciones desde actuales intereses ${ }^{74}, \mathrm{y}$ más adelante «yo sostengo que el autor de Juan 21, a la vez por el redactor de los capítulos 1-20, son extensivos al Grundschrift» ${ }^{75}$. El Grundschrift no conoce la idea de una huída de los discípulos. Thyen afirma la existencia de un cierto acento antidocetista en el Grundschrift. En

\footnotetext{
69 H. THYEN: Das Johannesevangelium. Mohr Siebeck, Tübingen 2006, 139.

70 Ibíd., 4.

71 Ibíd., Das Johannesevangelium, 136.

72 Cfr. H. THYEN: "Aus der Literatur zum Johannesevangelium", Theologische Rundschau 39 (1974)4, 308s; id., "Entwicklungen der Johanneischen Theologie und Kirche im Spiegel von Joh 21 und der Lieblingsjüngertexte des Evangeliums", 259-299, en M. de Jonge: L'evangile de Jean. Sources, rédaction, théologie. Leuven University Press, Leuven 1977; id., Das Johannesevangelium. Mohr Siebeck, Tübingen, 2006. La visión crítica a Thyen, cfr. D. M. SMITH: John among the Gospels. University South Carolina Press, Columbia 2001², 167-169.

73 Cfr. H. THYEN: Entwicklungen, 288.

74 Ibíd.

75 H. THYEN: Jesus und Jünger, den Jesus liebte, 261.
} 
todo caso, este fuerte acento del origen terreno de Jesús y el resultante de ese «ingenuo docetismo», diferencia el Grundschrift, el cual, no admite el dualismo de dos niveles en la paradoja del Dios hecho hombre, sino más bien la naturaleza sobre el origen humano sólo como «mala comprensión» (Jn 6, 41s) ${ }^{76}$. Thyen no dice que el Grundschrift fue docetista, sino que «ha tenido el peligro en esta dirección».

\section{Críticas y objeciones}

Como ya hemos comentado las críticas a la teoría de los estratos, una vez que Bultmann la propuso, no se hicieron esperar. Estas vinieron de distintas partes y apuntaron al aspecto teológico y metodológico de ésta. Sin duda, la crítica más aguda e inesperada en cierto modo, fue realizada por Käsemann y radica en que considera innecesario el recurso a fuentes para explicar la cristología joánica, así lo afirma Smith, según el cual E. Käsemann en realidad ha preguntado "si la teoría de las fuentes es necesaria» ${ }^{77}$. Para Käsemann, el carácter superfluo de la teoría radica en el equivocado punto de partida teológico que muestra la teoría. En cambio para otros autores, la crítica a la teoría de los estratos ha estado dirigida a la cuestión metodológica que la acompaña. Diversos autores sostienen una insuficiente teoría o conjunto de criterios lingüisticos y teológicos que permitan, de manera objetiva y no arbitraria, discriminar estratos o fuentes. Los autores constatan una argumentación circular para legitimar supuestos estratos en base a características lingǘsticas o de contenido teológico. En este sentido, D. Smith siguiendo a otros autores ha criticado ácidamente la metodología seguida por Bultmann. Según Smith, «las características de estilo son dichas para indicar sólo diferencias de contenido — es decir, material narrativo o discursos- más bien que reales diferencias de estilo» ${ }^{78}$. Es decir, siguiendo la crítica de otros autores, las diferencias de estilo son arbitrariamente colocadas para justificar supuestas diferencias de contenido.

La crítica a la metodología en autores como E. Ruckstuhl se dirige a demostrar la unidad literaria del cuarto evangelio, precisamente en base a criterios estilísticos. Éste critica a Bultmann justamente la falta de un set de criterios de orden lingüístico y estilístico para discriminar fuentes. E.

\footnotetext{
76 H. THYEN: Entwicklungen, 276.

77 D. M. SMiTH: "The source of the Gospel of John: An Assessment of the present State of the Problem", New Testament Studies 10 (1964), 2, 346.

78 Ya en la primeras obras se aprecia la actitud crítica al trabajo de Bultmann, cfr. W. Wilckens: Enstehungs, 4-5; D. M. Smith: The sources, 339; Cfr. H. Conzelmann: Grundriss der Theologie des Neuen Testaments, Mohr Siebeck, Tübingen, 19976, 361; D. M. SMITH: La teología del vangelio di Giovanni. Cambridge 1998.
} 
Schweizer ${ }^{79}$ ha seguido la misma línea abierta por Ruckstuhl, al indicar en su obra la unidad de estilo del cuarto evangelio, sosteniendo por consiguiente que la división de fuentes sobre esta característica parece imposible. Las características esgrimidas por Schweizer se encuentran dispersas en todo el evangelio. El autor no niega que en algunos casos el redactor final haya integrado elementos tardíos como el prólogo, o que 6, 51c-58 pertenezca a «la tradición de la comunidad». No obstante, la advertencia dada a E. Ruckstuhl señala que «(...) sin embargo permanece muy improbable para mí una fuente escrita fuera del prólogo y de la historia de milagros». Según Schweizer, es probable que el evangelista haya utilizado fuentes, algunas veces sin esenciales cambios, otras, más o menos fuertemente elaboradoras. Con todo, una nueva obra ha sido elaborada. En relación a la división entre discursos y narraciones, Schweizer indica que «no existen diferencias de estilo». Abundando en esta crítica a la teoría, señala H. M. Teeple que «hay una necesidad para el establecimiento de una metodología antes que muchos acuerdos sean alcanzados $»^{80}$. La cuestión por los criterios metodológicos que permiten una discriminación de fuentes y estratos se constata como improbable y poco eficaz.

Si desde un punto de vista lingǘstico sostienen los autores una insuficiente teoría o conjunto de criterios lingüisticos y teológicos que ayuden de modo objetivo a discriminar estratos o fuentes, desde un punto de vista más bien literario, afirman el carácter superfluo, innecesario de dicha teoría. Algunos autores como B. Lindars esgrimen opiniones críticas a una teoría de estratos o fuentes. Éste autor cuestiona la metodología de sourcecriticism $^{81}$. A su juicio, «la teoría presupone demasiado simple y rígidamente una distinción entre el evangelista y sus dos principales fuentes ${ }^{82}$. De manera similar, O. Cullmann, en Johannine circle, critica la solución de R. Brown to go too far ${ }^{83}$, y sostiene fundamentalmente dos momentos: en el primero, el evangelista hizo uso de tradiciones, no fuentes, de diverso origen y desarrolló la obra tal como la conocemos hoy. En un momento posterior un redactor o un grupo de redactores revisaron y completaron la obra. Cullmann advierte contra el intento de diseccionar diversos «estratos» o «fuentes» ya que «la lógica moderna y los modos de pensar moderno no son necesariamente los mismos que

79 Cfr. E. RuCKSTUHL: EGO EIMI Die religionsgeschichte Erkunft und theologische Bedeutung der Johanneischen Bildenreden (1939).

80 H. TEEPLE: "Methodology in source analysis of the fourth Gospel", Journal of Biblical Literature 81(1962), 279.

81 B. LiNDARs: Behind the Fourth Gospel. SPCK, London 1971, 27.

82 Ibíd., 22-23.

83 O. Cullmann: Johannine circle. SCM Press, London 1976, 4. 
estos del primitivo cristianismo, de tal modo que más que construir una idea sobre otra, el primitivo cristianismo debió más bien presentar la misma verdad desde diferentes perspectivas $\rangle^{84}$. También Udo Schnelle se agrupa en este conjunto de opiniones, a su juicio, «deben ser casi completamente excluidos como criterios de decisión» ${ }^{85}$. Otros autores posteriores, como Lanbbrantner, señala que «it is not possible, on the basis of the Gospel as it now exists, to reconstruct layers through it and to place them convincingly in form-critical categories» ${ }^{86}$, y repite la crítica de E. Käsemann y K. Berger, en el sentido de que el documento base es un «ideal construct 1$\rangle^{87}$.

Diversos autores sostienen el carácter innecesario o la insuficiente base para discriminar estratos y fuentes en base a criterios lingǘsticos y teológicos, así, por ejemplo, Schnackenburg ${ }^{88}$ y en relación a la misma teoría, critica a las diversas teorías de los estratos, específicamente dirigida a G. Richter que «la problemática explotación de diferencias lingüísticas y teológicas. Pero aún resulta más arriesgado el concluir un empeño redaccional de toda la obra a partir de unas observaciones aisladas» ${ }^{89}$. La "problemática explotación de diferencias lingüísticas y teológicas» a la cual se refiere Schnackenburg expresa el problema de la circularidad en la argumentación. En relación al recurso de contenidos teológicos, el interés de Schnackenburg radica en mostrar «lo cuestionable del método que de las diferencias de concepto y contenido pretende sacar con demasiada facilidad consecuencias a favor de diferentes estratos o autores» ${ }^{90}$.

En relación a la fuente semeia, Thyen critica a Bultmann que la argumentación es «altamente especulativa» y parece más bien motivada por los intereses del sistemático Bultmann que por el exégeta ${ }^{91}$. Lo cual lleva a $\mathrm{H}$. Thyen a protestar contra la forma de encontrar estratos tal como lo realiza G. Richter: «Debo decididamente refutar de considerar el evangelio simplemente como un compendio de concepciones teológicas

\footnotetext{
$84 \quad$ Ibíd.

85 U. SCHNELLE: Antidocetic Christology in the Gospel of John. Fortress Press, Minneapolis 1992,8 .

86 Ibíd., 11.

87 Ibíd.; K. BERGER: "Hellenistische Gattungen im Neuen Testament", $A N R W$ II/25, 2 (1984), 1034-1452, 1230s.

88 Cfr. R. SCHNACKENBURG: El evangelio, 14

89 Ibíd., 16.

90 Ibíd., 103.

91 Cfr. H. THYEN: Liegt dem Johannesevangelium eine Semeia Quelle zugrunde?, 444; id, "Aus der Literatur zum Johannesevangelium" (2 fortsetzung), Theologische Rundschau 39/4 (1974), 308-330s.
} 
que se encuentran disarmónicamente una al lado de la otra» ${ }^{92}$. Para este autor, «el evangelio actual es una obra literaria coherente que quiere ser interpretada como tal y no como simplemente un compendio de tradiciones joánicas o protocristianas». Y en relación con la fuente semeia se muestra escéptico a su existencia ${ }^{93}$. Para él, el último redactor es el cuarto evangelista, «el creador de esta obra en la cual por otro lado, se puede individuar fuentes y reelaboraciones redaccionales».

Desde un punto de vista más estrictamente teológico, algunos autores han criticado la introducción de problemas y contradicciones a partir de la teoría de los estratos, así, por ejemplo, J. Miranda, en Die Sendung Jesu im vierten Evangelium, ha sostenido que la investigación del desarrollo histórico teológico de las expresiones de envío hasta su cristalización en las formas de envío y el uso de éstas en el cuarto evangelio es un más fructífero método que «una arbitraria y pretendida división de fuentes, la que produce además de diferentes y contradictorias teorías» ${ }^{94}$. Para Miranda la presentación de Jesús como un profeta que postula esta teoría, en una de sus fases, «ist sie nur quellenbedingt» ${ }^{95}$, es decir, el uso arbitrario de la teología está en función de elaborar una teoría de los estratos. La cristología del envío presente en el cuarto evangelio presupone el modelo teórico del profeta escatológico ${ }^{96}$. Al contrario, este autor sostiene que el tema de Jesús como profeta escatológico está presente en todas las partes del evangelio de Juan: «éste tema está presente no sólo en las partes asignadas a la llamada fuente semeia o del Grundschriftı ${ }^{97}$. Como conclusión, señala que «el evangelista mismo y no sólo la semeia Quelle o la vorlage tiene a Jesús como el profeta escatológico, como Moisés».

\section{Algunas conclusiones}

En la investigación actual existe una actitud crítica frente a la teoría de los estratos, hasta el punto que pareciera que el recurso a criterios

\footnotetext{
92 H. THYEN: “Aus der Literatur zum Johannesevangelium” (4 Fortsetzung), Theologische Rundschau 43 (1978), 355.

93 Cfr. H. THYEN: Studien zum Corpus Iohanneum. Mohr Siebeck, Tübingen 2007, 452.

94 J. P. Miranda: Die Sendung Jesu im vierten Evangelium.Religions-und theologiegeschichtliche Untersuchungen zu den Sendungformeln.Verlag katholisches bibelwerk. Stuttgart 1977, 13; E. HAEnCHEN: “Der Vater, der Mich Gesandt Hat", New Testament Studies 9 (1962), 20816.

95 J. P. Miranda: Die Sendung, 47.

96 Ibíd., 27.

97 Ibíd., 13; E. HAENCHEN: "Der Vater...”.
} 
estilísticos, de vocabulario y teológicos no sólo resulta insuficiente sino que también se muestra innecesario a la hora de formular la unidad y formación de la cristología joánica. A la luz de lo dicho, la situación postula la necesidad de buscar un nuevo punto de partida, un contexto más amplios u otro tipo de criterios hermenéuticos que ayude a comprender la totalidad de la obra joánica. Así, por ejemplo, el estudio del trasfondo ideológico de grupos marginales del judaísmo tardío, es decir, grupos apocalípticos, samaritanos o esenios otorga conceptos literarios y teológicos que suministran una función heurística para distinguir qué se entiende por texto religioso, cómo se genera éste dentro de una comunidad que comparte una matriz ideológica común. Es importante hacer notar que la cuestión sobre el trasfondo y la teoría de los estratos son dos cuestiones distintas y que se justifican independientemente; sin embargo, Thyen aporta sugerentes luces por medio de la categoría de la intertextualidad del cuarto evangelio.

En el ámbito de la crítica literaria, se reconoce, por una parte, un avance metodológico en cuanto que la nueva crítica literaria se muestra más cauta a la hora de esbozar una teoría y, por otra, que las ampliaciones o relecturas, que proponen los diversos autores, están orientadas por la idea que tales añadidos o ampliaciones tuvieron un determinado fin literario o teología, perdiendo el carácter arbitrario de la antigua crítica. Además, dentro de los elementos metodológicos integrados en esta nueva crítica, R. Schnackenburg ${ }^{98}$ enumera: la incorporación de $1 \mathrm{Jn}$, la cual se utiliza como clave hermenéutica para comprender las ideas e intenciones del redactor; y la indicación de diferencias conceptuales entre el evangelista y la redacción. A esto habría que añadir que el concepto de texto que utiliza la teoría de los estratos es inadecuada, ya que el texto religioso, según se aprecia en los textos de Qumrán, no pertenece a un autor sino a una comunidad, el cual es elaborado por múltiples manos y asume el carácter de intertexto, el cual más bien tiene como autor a la propia comunidad que se comprende a la luz de estos escritos.

Como lo hemos mostrado en nuestro estudio, para diversos autores como E. Häenchen, G. Richter y J. Becker, la naturaleza de la primera fase es comprendida de diferente manera, en algunos casos se trata de tradiciones sueltas y orales o un Vorlage, un sermón, un Grundschrift o un Grundevangelium. Finalmente, otros establecen una cierta relación entre la fuente semeia y un Grundschrift o Grundevangelium. En algunos casos, esta relación va desde la idea que este Grundevangelium habría sido algo así como un Zeichenevangelium o un Grundstuck como en el caso de Becker. En 
cuanto a los contenidos cristológicos del Grundschrift, la mayoría de estos autores, L. Boismard, G. Richter, L. Martyn, R. Brown, sostiene que en la primera etapa, tradiciones orales o un Grundevangelium, contenía una cristología del profeta escatológico como Moisés. Otros pocos, como W. Wilckens, tienden a señalar que los materiales pertenecientes a este Grundevangelium tienen como cristología al mesías Hijo de Dios, apoyándose en los textos de Jn 1, 19-34; 20, 30. En cambio, en autores como Fortna, Richter, Borgen prevalece la idea de que la tipología mosaica que utiliza el Grundschrift está referida a la figura del profeta escatológico entendido como un ser bumano de tipo nacionalista distinta a la que presentan los discursos. En algunos casos, como Borgen, se establece la polaridad profeta escatológico (ser humano)-Hijo del hombre (origen divino). A nuestro juicio injustificadamente, ya que el origen humano o divino del profeta no se identifica con la cuestión de la naturaleza de ese enviado. En estudios realizados en otros lugares, hemos demostrado que la convicción de un hombre entronizado y de un profeta mesías fueron expectativas presentes en movimientos marginales como el enoquismo y esenismo del siglo II y I a.C. Al contrario de lo que piensa G. Richter, el estatuto divino del «hombre» y del profeta escatológico está acreditado en los textos apocalípticos y en Qumrán. Nuestra investigación ha demostrado que estas creencias encontradas en la literatura de Qumrán ofrecen datos suficientemente claros para afirmar que en el cambio de era, se creía que figuras del pasado o ángeles serían enviados a la tierra con la misión de realizar el juicio divino en los últimos tiempos. El material narrativo y los discursos revelan una misma cristología, las diferencias de estilo son evidentes, pero éstas se explican porque el evangelista bien pudo haber tenido en su poder tradiciones tipo sinópticas pero que han tenido la cristología del profeta escatológico como característica particular. Como lo señalan diversos autores, tales como R. Fortna y P. Borgen, los relatos del ciclo de Juan el Bautista y de la multiplicación de los panes muestran contactos con los relatos sinópticos sin embargo nos parece que no se identifica con éstos. A partir del estudio que hemos realizado acerca de los orígenes de la cristología joánica desde la tradición de 11QMelq nos atrevemos a lanzar la siguiente pregunta: ¿cómo se puede postular la existencia de pretendidos estratos cuando estos rasgos teológicos esparcidos en diferentes partes del evangelio provienen íntegros de una misma matriz ideológica? El supuesto de estas teorías radica en la arbitraria hipótesis de la existencia de diferentes cristologías subyacentes a través del evangelio joánico. Los textos de 11QMelq, 4Q521; 4 Q377 colocan en cuestión la necesidad de un supuesto Grundschrift o fases para explicar la unidad literaria y teológica del cuarto evangelio. En estos textos encontramos diferentes 
aspectos de la expectativa del profeta escatológico presentados simultáneamente, según estos autores, en el cuarto evangelio como estratos.

Sumario: Introducción; 1. El problema de la unidad literaria y teológica; 1.1. La existencia de tradiciones o un Vorlage; 1.2. El recurso a un Grundschrift o Semeia Quelle; 1.3. Soluciones híbridas; 2. Críticas y objeciones; 3. Algunas conclusiones. 